\title{
Hiri Motu Language
}

National Cancer Institute

\section{Source}

National Cancer Institute. Hiri Motu Language. NCI Thesaurus. Code C153949.

A simplified version of Motu that is an official language of Papua New Guinea. 